\title{
SMOS based high resolution soil moisture estimates for desert locust preventive management
}

\author{
Maria Jose Escorihuela ${ }^{\mathrm{a}, *}$, Olivier Merlin ${ }^{\mathrm{b}}$, Vivien Stefan ${ }^{\mathrm{a}}$, Gorka Moyano ${ }^{\mathrm{a}}$, Omar Ali Eweys ${ }^{\mathrm{a}, \mathrm{c}}$, \\ Mehrez Zribi $^{\mathrm{b}}$, Sidi Kamara ${ }^{\mathrm{d}}$, Ahmed Salem Benahi ${ }^{\mathrm{d}}$, Mohamed Abdallahi Babah Ebbe ${ }^{\mathrm{e}}$, \\ Jamal Chihrane ${ }^{\mathrm{f}}$, Saïd Ghaout ${ }^{\mathrm{f}}$, Sory Cissé ${ }^{\mathrm{g}}$, Fakaba Diakitég ${ }^{\mathrm{g}}$, Mohammed Lazar $^{\mathrm{h}}$, \\ Thierry Pellarin ${ }^{\mathrm{i}}$, Manuela Grippa ${ }^{\mathrm{j}}$, Keith Cressman ${ }^{\mathrm{k}}$, Cyril Piou ${ }^{\mathrm{f}, 1, \mathrm{~m}}$ \\ a isardSAT, Parc Tecnològic Barcelona Activa, Carrer Marie Curie 8 - 14, 08042 Barcelona, Spain \\ ${ }^{\mathrm{b}}$ CESBIO, Université de Toulouse, IRD, UPS, CNRS, CNES, Toulouse, France \\ ' Soil Sciences Department, Faculty of Agriculture, Cairo University, 6 El Gamaa st, 12613 Giza, Egypt \\ d Centre National de Lutte Antiacridienne (CNLA), Nouakchott BP 665, Mauritania \\ e DG Institut du Sahel/CILSS, Bamako B.P:1530, Mali \\ ${ }^{\mathrm{f}}$ Centre National de Lutte Antiacridienne, Aï, Melloul (CNLAA), Inezgane, BP 125, 86343 Agadir, Morocco \\ ${ }^{g}$ Centre National de Lutte contre le Criquet pélerin (CNLCP), BP E-4281, Rue 313, Porte 261, Quartier du fleuve, Bamako, Mali \\ ${ }^{\mathrm{h}}$ Institut National de la Protection des Végétaux (INPV), Alger, Algeria \\ ${ }^{\mathrm{i}}$ Laboratoire d'étude des Transferts en Hydrologie et Environnement, Grenoble, France \\ ${ }^{\mathrm{j}}$ Géosciences Environnement Toulouse (Université de Toulouse, CNRS, IRD), France \\ ${ }^{\mathrm{k}}$ Food and Agriculture Organization of the United Nations (FAO), Rome, Italy \\ ${ }^{1}$ CIRAD, Univ Ibn Zohr, Agadir, Morocco \\ ${ }^{\mathrm{m}}$ UMR CBGP, Univ Montpellier, CIRAD, INRA, IRD, SupAgro, Montpellier, France
}

\section{A R T I C L E I N F O}

\section{Keywords:}

Remote sensing

Soil moisture

Desert locust management

West Africa

SMOS

Disaggregation

Sentinel-1

\begin{abstract}
A B S T R A C T
This paper presents the first attempt to include soil moisture information from remote sensing in the tools available to desert locust managers. The soil moisture requirements were first assessed with the users. The main objectives of this paper are: i) to describe and validate the algorithms used to produce a soil moisture dataset at $1 \mathrm{~km}$ resolution relevant to desert locust management based on DisPATCh methodology applied to SMOS and ii) the development of an innovative approach to derive high-resolution $(100 \mathrm{~m})$ soil moisture products from Sentinel-1 in synergy with SMOS data. For the purpose of soil moisture validation, 4 soil moisture stations where installed in desert areas (one in each user country). The soil moisture $1 \mathrm{~km}$ product was thoroughly validated and its accuracy is amongst the best available soil moisture products. Current comparison with in-situ soil moisture stations shows good values of correlation $\left(\mathrm{R}>0.7\right.$ ) and low RMSE (below $0.04 \mathrm{~m}^{3} \mathrm{~m}^{-3}$ ). The low number of acquisitions on wet dates has limited the development of the soil moisture $100 \mathrm{~m}$ product over the Users Areas. The Soil Moisture product at $1 \mathrm{~km}$ will be integrated into the national and global Desert Locust early warning systems in national locust centres and at DLIS-FAO, respectively.
\end{abstract}

\section{Introduction}

Desert locusts are a type of grasshopper found primarily in the Sahara, across the Arabian Peninsula and into India. The insect is usually harmless, but when they swarm they can migrate across long distances and cause widespread crop damage. In 2003-2005, eight million people in over 20 countries suffered from ravages caused by swarms of Desert locusts, with an estimated $80-100 \%$ of crops lost in afflicted regions, mostly sub-Saharan Africa (Brader et al., 2006).
Plagues of Desert locusts, Schistocerca gregaria (Forskål 1775), have threatened agricultural production in Africa, the Middle East, and Asia for centuries. The livelihood of at least one-tenth of the world's human population can be affected by swarms of this insect (Latchininsky et al., 2016).

The Desert locust is able to change from a solitarious phase when population density is low to a gregarious phase when population density is high (Uvarov, 1921; Pener and Simpson, 2009). The major driver of this phase transformation is population growth and concentration in

\footnotetext{
* Corresponding author.

E-mail address: MJ.Escorihuela@isardSAT.cat (M.J. Escorihuela).

URL: http://www.isardSAT.cat (M.J. Escorihuela).
} 
the vegetated part of desert areas. Sporadic and localized rains cause vegetation growth and allow these population to increase through egg deposition in wet sandy soil and good survival in the developing vegetation. The new vegetation provides food for the newly hatched locusts and shelter as they develop into winged adults.

Desert locust preventative management aims to prevent crop damage by controlling populations before they can reach high densities, go through phase change and form mass migrating swarms (Brader et al., 2006; Magor et al., 2008). The areas of potential gregarization for desert locust are large (estimated to at least 0.25 million $\mathrm{km}^{2}$ Sword et al., 2010) and need to be physically assessed by survey teams for efficient preventative management. To achieve early detection, survey teams from each country must visit potential breeding areas to assess the condition of habitat and the state of any desert locust population. The potential breeding habitats cover enormous areas that are often remote and difficult of access. An on-going challenge is to be able to guide where surveys should occur depending on local meteorological and vegetation conditions.

To guide survey teams precisely to those areas with highest probability for desert locust breeding, satellite imagery represents an invaluable tool because it has the potential to provide an indication of the evolution of vegetation cover and soil moisture, which are the two main parameters for describing desert locust habitat. During the 1980s, the Desert Locust Information Service (DLIS) from FAO started to use earth observation techniques to assess environmental conditions (Hielkema et al., 1990; Cressman and Hodson et al., 2009). Meteosat cloud imagery was the first satellite imagery used by FAO-DLIS to estimate rainfall areas. Few years later the NOAA/AVHRR $7 \mathrm{~km}$ resolution Normalised Difference Vegetation Index (NDVI) gave information on vegetation. Currently, FAO-DLIS advises the countries to use greenness maps to verify the potential habitats of desert locust (Pekel et al., 2011; Waldner et al., 2015; Renier et al., 2015). These greenness maps are produced based on MODIS imagery to show the changes of vegetation providing the greening of vegetation and its disappearance at a pixel resolution of $250 \mathrm{~m}$. The FAO also promotes the use of daily, decadal, and monthly geo-referenced satellite-derived rainfall estimates on a $0.25^{\circ} \times 0.25^{\circ}$ latitude/longitude grid (Dinku et al., 2010; Cressman, 2013).

Using vegetation status alone can lead desert locust managers to a temporal problem to decide when to send survey teams. Indeed, NDVI or derived vegetation greenness maps might arrive to the managers at the same time than locust populations actually develop. To be able to take earlier the decision to send survey teams, one solution is to have timely information about soil moisture, which precedes vegetation growth. Soil moisture (SM) is a very good indicator of reproduction potential over an area, since desert locust females choose and need moist areas to lay their eggs (Hunter-Jones, 1964; Pener and Simpson, 2009). In comparison to rainfall, SM allows to focus on areas where reproduction might happen. Second, the rain falling on mountain areas can spread over several hundreds of kilometres, and hence favours vegetation development and reproduction of desert locust in areas far away from the rainfall event (Lazar et al., 2016). On the long run, SM could also be incorporated in decision support systems based on statistical models coupling satellite imagery to field reality.

The Soil Moisture for dEsert Locust earLy Survey (SMELLS) project (http://smells.isardsat.com/) has been the first attempt to include SM information from remote sensing in the tools available to desert locust managers. The project first step was to assess the users requirements for the soil moisture products. The panel of users primarily constituted for SMELLS was of 4 affected countries by desert locust in western and northern Africa (Algerian INPV, Malian CNCLP, Mauritanian CNLA and Moroccan CNLAA) and one international institution dealing with the transmission of Desert locust information (FAO-DLIS). The geographical and temporal requirements of these users are therefore different. A consensus appeared to have the SM produced per decades (10 days). This can be justified by the fact that 10 days, or more precisely the decades of the month (10 first days, 10 following days, 8-11 left-over days), is the temporal unit of desert locust management in terms of information transfer and reports when an outbreak or upsurge is developing. Also, many other EO products used in Desert locust early warning system and preventive management are now produced following this decadal system (e.g. the IRI decadal rain estimates). The accepted latency is between 3 and 10 days. The spatial resolution required is varying among users, but always equal or below $300 \mathrm{~m}$. This corresponds to the need of the identification of small spatial structures corresponding to favourable biotopes, such as wadis where water accumulate and will become perfect habitats for Desert locust reproduction.

Currently, the soil moisture data sets available at global scale have a spatial resolution much coarser than that required by locust managers. Specifically, the soil moisture retrieved from passive microwave observations such as Advanced Microwave Scanning Radiometer-EOS (AMSR-E) (Njoku et al., 2003), Soil Moisture and Ocean Salinity (SMOS) (Kerr et al., 2001) or Soil Moisture Active and Passive (SMAP) (Entekhabi et al., 2010) have a spatial resolution of about $40 \mathrm{~km}$.

Hydrological, agricultural and water management applications have been also requesting soil moisture datasets at a higher resolution for a long time now. In this context, downscaling methodologies have been developed to improve the spatial resolution of readily available passive microwave-derived soil moisture data. In particular, the DisPATCh disaggregation scheme estimates the soil moisture variability at high resolution within a low resolution pixel by relying on a self-calibrated evaporation model (Merlin et al., 2013). The DisPATCh algorithm has been implemented and validated in several climatic regions such as Catalonia, Spain (Merlin et al., 2012, 2013), Central Morocco (Merlin et al., 2015), South-Eastern Australia (Malbéteau et al., 2016) and two watersheds in the USA (Molero et al., 2016). However, it has never been tested in the arid regions where the desert locust is likely to reproduce.

In the microwave domain, active sensors (radars) achieve a spatial resolution much finer than that of radiometers. Sentinel-1 A and B (Torres et al., 2012) are providing C-band SAR (Synthetic Aperture Radar) data at a spatial resolution of about $20 \mathrm{~m}$. Although backscatter data have potential to monitor SM (Balenzano et al., 2013), there is currently no operational soil moisture product at such fine resolution. This is notably due to the difficulty to model in time and over extended areas the impact of vegetation cover/structure and surface roughness on the backscatter signal (Satalino et al., 2014), and thus the need for site-specific calibration (Zribi et al., 2011).

One widely used approach when a long time series of backscatter exist over one site is to set the lowest and highest values of the observed backscatter to the lowest and highest values of soil moisture. The soil moisture data are then provided in terms of degree of saturation, that is, in relative units ranging between 0 (dry) and 100 (saturated). This is for example the approach used in H-SAF Soil Moisture product from ASCAT (Wagner et al., 1999). The main drawbacks of this approach are that soil moisture is provided as a relative quantity (not measurable) and that outliers may disrupt relation. Another widely used approach, when the time series is not long enough and/or in-situ soil moisture data are available, is to use these in-situ measurements to calibrate a linear relationship between soil moisture and backscatter (Zribi et al., 2011). The advantage of this approach compared with the previous one is that it provides absolute soil moisture values (measurable). Its main drawback is that it is completely site dependant since it depends on the insitu soil moisture measurements. Here we propose a methodology based on the second approach. What is innovative in our approach is that we will be relying in passive microwave disaggregated soil moisture instead of in-situ measurements to calibrate those widely validated methods to derive soil moisture from SAR measurements. In a recent analysis from Louvet et al., 2015, different soil moisture products at low resolution (around $40 \mathrm{~km}$ ) where evaluated over West Africa (Louvet et al., 2015). The products analysed were SMOS, AMSR-E NSIDC, AMSR-E VUA and ASCAT. In Louvet et al., 2015 best performances 


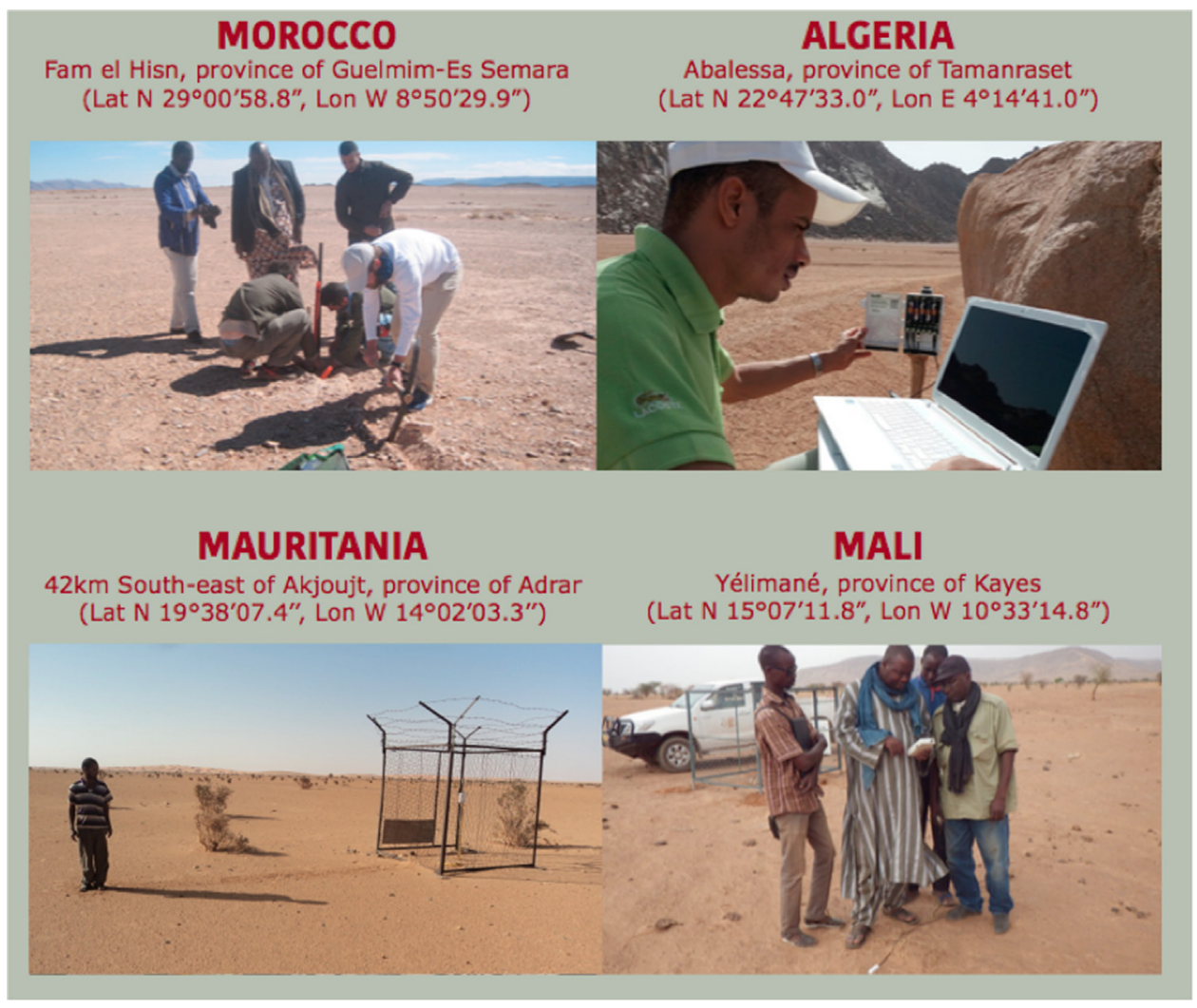

Fig. 1. SMELLS Soil Moisture Stations.

were for SMOS with a correlation coefficient (R) of 0.7 and a root mean square error (RMSE) of $0.032 \mathrm{~m}^{3} \mathrm{~m}^{-3}$. Using SMOS disaggregated soil moisture as 'ground truth' will allow at the same time to i) obtain absolute soil moisture values (measurable) and ii) be site independent since our disaggregation scheme is self-calibrated (i.e. no need for ancillary information).

In this context, the main objectives of this paper are: i) to describe and validate the algorithms used to produce a soil moisture dataset at $1 \mathrm{~km}$ resolution relevant to desert locust management based on DisPATCh methodology applied to SMOS and ii) the development of an innovative approach to derive high $(100 \mathrm{~m})$ resolution soil moisture products from Sentinel-1 (S1) in synergy with SMOS data.

\section{Datasets}

The development of SM products and their analysis has been carried out in 4 countries affected by desert locust in western and northern Africa: Algeria, Mali, Mauritania and Morocco that participate in the SMELLS project. The time period used for analysis is from January 2010 till December 2016.

\subsection{Soil moisture from remote sensing data}

ESA's SMOS mission has been designed to observe SM over the Earth's landmasses and salinity over the oceans. Launched on 2 November 2009, SMOS is the second Earth Explorer Opportunity mission developed as part of ESA's Living Planet Programme.

An important aspect of this mission is to demonstrate a new measuring technique in the field of Earth observation. SMOS carries the first-ever, polar-orbiting, space-borne, 2D interferometric radiometer operating at the lowest protected band of microwaves. Its Microwave Imaging Radiometer using Aperture Synthesis (MIRAS) measures microwave radiation around the frequency of $1.4 \mathrm{GHz}$ (L-band).

In SMOS L2 products, multiangular observations of brightness temperature (TB) are used to retrieve simultaneously SM and vegetation optical depth at nadir $\left(\tau_{N A D}\right)$ using a standard iterative minimization approach of a cost function. The main component of the cost function is given by the sum of the squared weighted differences between measured and modelled TB data, for a variety of incidence angles. The algorithm finds the best set of the parameters, e.g., SM and vegetation characteristics, which drive the direct TB model and minimizes the cost function (Kerr et al., 2012).

\subsection{MODIS}

MODIS (Moderate Resolution Imaging Spectroradiometer) is a key instrument aboard the Terra and Aqua satellites. Terra's orbit around the Earth is timed so that it passes from north to south across the equator in the morning, while Aqua passes south to north over the equator in the afternoon. Terra MODIS and Aqua MODIS are viewing the entire Earth's surface every 1-2 days, acquiring data in 36 spectral bands.

Our algorithms need Land Surface Temperature (LST) and NDVI, so we rely on two different MODIS L3 products:

- MODIS Aqua and Terra Land Surface Temperature and Emissivity Daily L3 Global $1 \mathrm{~km}$ Grid SIN.

- MODIS/Terra Vegetation Indices 16-Day L3 Global 1 km Grid SIN.

\subsection{Sentinel-1}

The Sentinel-1 (S1) mission comprises a constellation of two polarorbiting satellites, performing C-band Synthetic Aperture Radar (SAR) imaging. S1A was launched on 3 April 2014 and S1B was launched on 25 April 2016.

The C-band SAR on board S1 is measuring at a central frequency of $5.405 \mathrm{GHz}$ at multi-polarisation and with variable swath/resolution. S1 has four modes, but over land it is operated mainly in Interferometric 
Wide Swath (IWS) mode which images the Earth at $5 \times 20 \mathrm{~m}$ spatial resolution at VV and $\mathrm{VH}$ polarisation.

\subsection{In-situ soil moisture}

During the first quarter of 2016, a SM station was installed in each of the participating countries within the Users Areas of Interest. The basic set up consists of 2 surface sensors at $5 \mathrm{~cm}$ depth and 1 sensor at $15 \mathrm{~cm}$ depth. SM sensors are Decagon EC-5 and default calibration is used. The stations are located in desert areas of remote access where vegetation is extremely scarce (see Fig. 1 ). The exact location, soil texture values from the Ecoclimap (Masson et al., 2003) and Soil Grid database (soilgrids.org) and used dataset is detailed below:

- Fam el Hisn Station (Lat N 2900'58.8”, Lon W 850'29.9”), located in the province of Tata, Morocco installed in March 24th, 2016. The sand (S) percentage is estimated to be between $39 \%$ and $57 \%$ and clay (C) between $22 \%$ and $24 \%$ according to ecoclimap and soilgrids respectively. The dataset extends from March 24th, 2016 until October 27th, 2017

- Abalessa Station (Lat N 22 47'33.0”, Lon E 4¹4'41.0”), province of Tamanraset, Algeria installed April 19th, 2016. The S percentage is between $44 \%$ and $55 \%$ and $C$ between $22 \%$ and $32 \%$. The dataset extends from April 19th, 2016 until December 25th, 2016

- Yélimané Station (Lat N 1507'11.8”, Lon W 10³3'14.8”), province of Kayes, Mali installed May 13th, 2016. The S percentage is between $58 \%$ and $64 \%$ and $C$ between $21 \%$ and $30 \%$. The dataset extends from May 13th, 2016 until October 21th, 2017

- Akjoujt Station (Lat N $19^{\circ} 38^{\prime} 07.4^{\prime \prime}$, Lon W $14^{\circ} 02^{\prime} 03.3$ "), province of Adrar, Mauritanie installed May 20th, 2016. The S percentage is between $68 \%$ and $80 \%$ and $C$ between $12 \%$ and $16 \%$. The dataset extends from May 20th, 2016 until August 13th, 2017

Because of the relatively short-time SM dataset from the SMELLS stations, the long-term measurements of the in-situ soil moisture data from the AMMA-CATCH sites in Mali and Niger have been also used for validation purposes.

The AMMA-CATCH Mali site is located in the semi-arid Sahelian area. Climatic conditions are governed by the West African Monsoon with a long dry season and a shorter rainy season from July to September. The AMMA-CATCH Mali site is characterised by a mean annual rainfall of $370 \mathrm{~mm}$ per year (over 1920-2005). We have used data from the Agoufou site (Lat N $15^{\circ} 20^{\prime} 24^{\prime \prime}$, Lon W $1^{\circ} 28^{\prime} 26.4^{\prime \prime}$ ) that consists of 2 sensors at $5 \mathrm{~cm}$ depth. The texture of the sites is $\mathrm{S}$ percentage $95 \%$ and C percentage 1\% (De Rosnay et al., 2009). Sensors provide soil moisture at the hourly time step, for the period 2010-2011.

The AMMA-CATCH Niger site, consists of 3 sampling plots each with 2 sensors at $5 \mathrm{~cm}$ depth. The texture of the sites is $S$ percentage $77 \%$ and C percentage $8 \%$ (Pellarin et al., 2009). The exact location is given below:

- Wankama site (Lat N $13^{\circ} 38^{\prime} 45.5^{\prime \prime}$, Lon E $\left.2^{\circ} 37^{\prime} 55.2^{\prime \prime}\right)$

- Banizoumbou site (Lat N 13 31'28.92", Lon E $\left.2^{\circ} 39^{\prime} 36^{\prime \prime}\right)$

- Tondikiboro site (Lat N $13^{\circ} 32 ' 52^{\prime \prime}$, Lon E $2^{\circ} 41^{\prime} 45.6^{\prime \prime}$ )

AMMA-CATCH Niger sensors provide soil moisture at the hourly time step, for the period 2010-2014.

Both AMMA CATCH sites Soil Moisture sensors are CS-616 and default calibration is used.

\section{SMELLS products}

\subsection{SMELLS $1 \mathrm{~km}$ product}

In the framework of the SMELLS project, the DisPATCh algorithm to disaggregate SMOS SM was implemented in West Africa $\left(40-10^{\circ} \mathrm{N}\right.$, $20^{\circ} \mathrm{W}-20^{\circ} \mathrm{E}$ ). DisPATCh provides $1 \mathrm{~km}$ resolution SM data from coarse-scale microwave-derived SM. In DisPATCh, the soil evaporation from the $0-5 \mathrm{~cm}$ soil layer and the vegetation transpiration from the root zone soil layer are partitioned by separating MODIS LST (Land Surface Temperature) into its soil and vegetation components. The partitioning method relies on a contextual interpretation of MODIS LST and MODIS NDVI (Moran et al., 1994). MODIS-derived soil temperature is first used to estimate Soil Evaporative Efficiency (SEE) defined as the ratio of actual to potential soil evaporation, which is known to be relatively constant during the day on clear sky conditions. DisPATCh then distributes high-resolution soil moisture around the low-resolution observed mean value using the instantaneous spatial link between optical-derived SEE and near-surface soil moisture (Malbéteau et al., 2016). The downscaling relationship is written as:

$S M_{1 \mathrm{~km}}=S M_{40 \mathrm{~km}}+\left(\frac{\delta S M_{m o d}}{\delta S E E}\right)_{40 \mathrm{~km}} x\left(S E E_{1 \mathrm{~km}}-\left\langle S E E_{1 \mathrm{~km}}\right\rangle\right)$

with being $S M_{40 \mathrm{~km}}$ the SMOS level 2 soil moisture, $S E E_{1 \mathrm{~km}}$ the MODIS derived soil evaporative efficiency (SEE), $\left\langle S E E_{1 \mathrm{~km}}\right\rangle$ its average within a SMOS pixel and $\delta S M_{\text {mod }} / \delta S E E$ the partial derivative evaluated at SMOS scale of soil moisture with respect to SEE. MODIS derived soil evaporative efficiency is expressed as

$S E E_{1 \mathrm{~km}}=\frac{T_{s, \max }-T_{s}}{T_{s, \max }-T_{s, \min }}$

with being $T_{S}$ the MODIS derived soil skin temperature, $T_{S, \max }$ the soil skin temperature in dry conditions (at $S E E=0$ ) and $T_{s, \min }$ the soil skin temperature in wet conditions (at $S E E=1$ ). In this study, $T_{s, \text { min }}$ is estimated as the minimum MODIS LST within the SMOS pixel. MODIS derived soil skin temperature is estimated as

$T_{s}=\frac{T_{M O D I S}-f_{v} T_{v}}{1-f_{v}}$

with $T_{\text {MODIS }}$ being the $1 \mathrm{~km}$ resolution MODIS land surface temperature, $f_{v}$ the MODIS derived fractional vegetation cover and $T_{v}$ the vegetation temperature. In this study vegetation temperature in Eq. (3) is estimated at 1-km resolution with the "hourglass" approach in [Moran et al., 1994].

A linear approximation for the SEE model (Manabe, 1969) was used as in Merlin et al. (2013), Molero et al. (2016):

$S E E_{m o d}=\frac{S M}{S M_{p}}$

with $S M_{p}$ being a soil parameter.

The algorithm uses when available ascending and descending passes of SMOS L2, MODIS/Terra 16-day vegetation indices and MODIS Terra and Aqua daily land surface temperature $1 \mathrm{~km}$ grid product. The SMOS L2 products available from ESA are the nominal soil moisture products and use the mission operational processing chain. Products are available within a $12 \mathrm{~h}$ delay since data sensing.

The processing is divided in the steps illustrated in Fig. 2:

- Preliminary registration (only for MODIS input products): the MODIS input products are projected onto a rectangular grid.

- Common grid projection: the input products are all projected into a common grid, this way they can easily be combined, regardless of the original type or size of the input files.

- Disaggregation: the SMOS and MODIS products that share location and time are combined using the DisPATCh disaggregation algorithm.

- Temporal averaging: in order to have a file per monthly-decade, all the DisPATCh output files in a decade are averaged.

- Spatial merging: in order to have a single file per macro-region, all the sub-region (12 MODIS tiles) are spatially merged.

- Geotiff conversion: the ASCII grid output files are converted into 


\section{\begin{tabular}{l|l|l|l|l} 
SMUDP2 & MOD11A1 MYD11A1 MOD13A2
\end{tabular}}
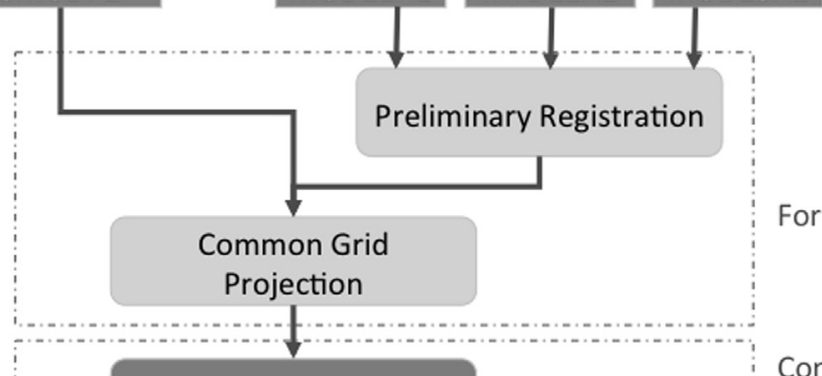

For each input file

Combining SMOS and

Disaggregation

MODIS data in a same

location and time

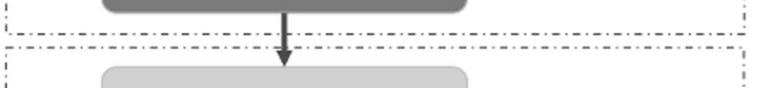

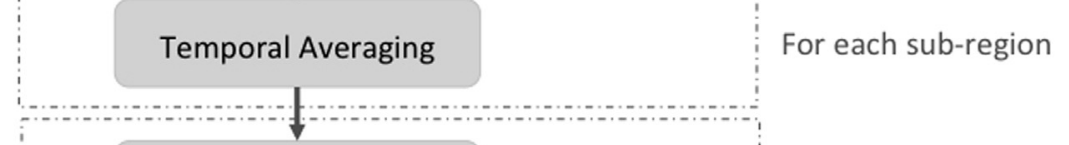

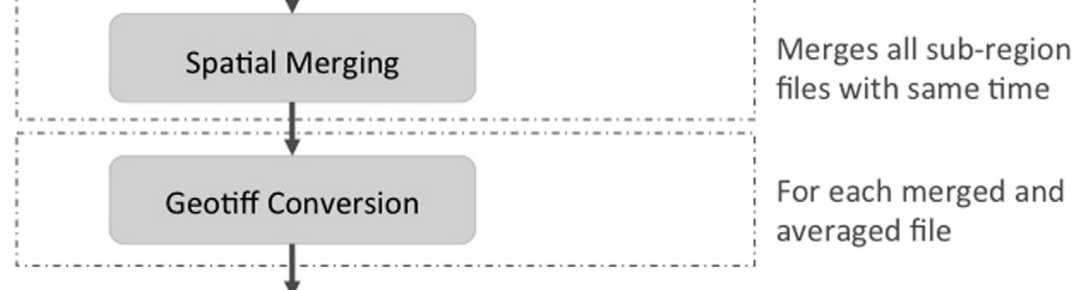

SMELLS $1 \mathrm{~km}$

Fig. 2. SMELLS $1 \mathrm{~km}$ soil moisture products processing flow.

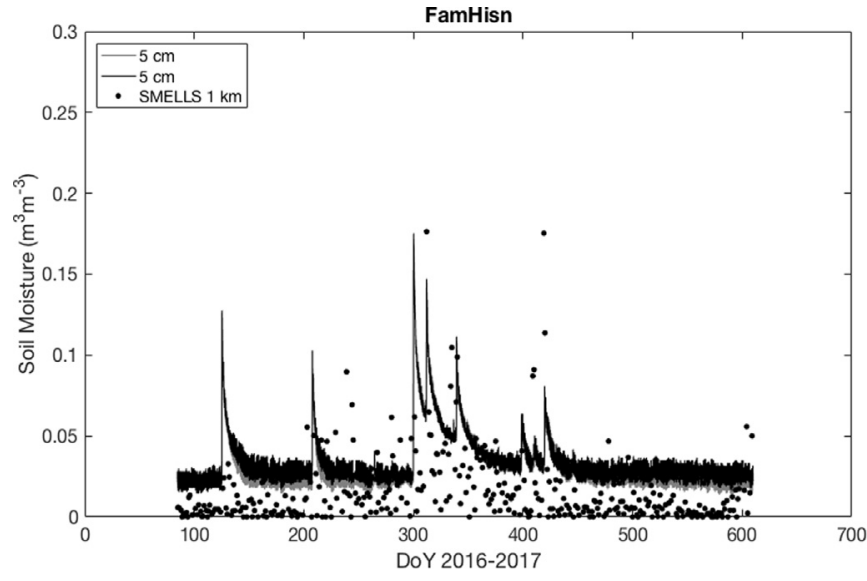

Fig. 3. Fam el Hisn in-situ measurements and SMELLS $1 \mathrm{~km}$ product temporal evolution.

Geotiff images using a color code agreed with users with the purpose of enhancing relevant soil moisture range.

\subsection{SMELLS $100 \mathrm{~m}$ product}

The development of the SM $100 \mathrm{~m}$ product is based on the following hypothesis:

- The temporal variations of the backscatter at the pixel resolution are mainly due to soil moisture variations (i.e. roughness and/or vegetation variations are neglected). In that case, the sensitivity of backscatter to soil moisture is expected to be positive i.e. backscatter increases with soil moisture because reflectivity increases due to the higher dielectric constant of wet soil with respect to dry soil (Ulaby et al., 1986).

- The averaged high resolution $(100 \mathrm{~m})$ soil moisture at the $1 \mathrm{~km}$ scale should be equal to the $S M_{1 \mathrm{~km}}$

The processing of $\mathrm{S} 1$ data follows the typical procedure: calibration, multilook, terrain-correction and speckle filter. The backscatter is estimated in $\mathrm{dB}$ at the $100 \mathrm{~m}$ resolution on a fixed grid defined within the Users Areas of Interest. For the angular correction, considering that all pixels are within desert areas with scarce vegetation, the hypothesis is made that the same correction is applicable to all pixels. Azimutal angle variations are taken into account by processing separately ascending and descending passes.

We estimate the backscatter sensitivity to soil moisture in each high resolution pixel using the following relationship:

slope $_{100 m}=\frac{d B_{w e t}-d B_{d r y}}{S M_{w e t}-S M_{d r y}}$

where $d B_{\text {wet }}$ is the backscatter (in $\mathrm{dB}$ ) of the $\mathrm{S} 1$ image on the wet day, $d B_{d r y}$ is the backscatter (in $\mathrm{dB}$ ) of the $\mathrm{S} 1$ image on the dry day, $S M_{\text {wet }}$ is the $S M_{1 \mathrm{~km}}$ on the wet day and $S M_{d r y}$ is the $S M_{1 \mathrm{~km}}$ on the dry day.

Then we average slope $e_{100 \mathrm{~m}}$ over the $1 \mathrm{~km}$ pixel to estimate slope $_{1 \mathrm{Km}}$.

slope $_{1 \mathrm{~km}}=\frac{1}{N} \sum$ slope $_{100 \mathrm{~m}}$

where $\mathrm{N}$ is the number of $100 \mathrm{~m}$ pixels within the $1 \mathrm{~km}$ pixel (i.e $\mathrm{N}=100$ ).

Negative values of slope are not possible according to our first hypothesis, we thus set slope $_{1 \mathrm{~km}}$ equal to 0 when a negative value is estimated. This sensitivity $\left(\right.$ slope $_{1 \mathrm{~km}}$ ) is then used to estimate the highresolution soil moisture $s_{100 \mathrm{~m}}$ using the following equation:

$s m_{100 \mathrm{~m}}=\frac{d B_{\text {wet }}-d B_{d r y}}{\text { slope }_{1 \mathrm{~km}}}+S M_{d r y}$

The high resolution soil moisture satisfies the following equation:

$S M_{1 k m}=\frac{1}{N} \sum S m_{100 m}$ 

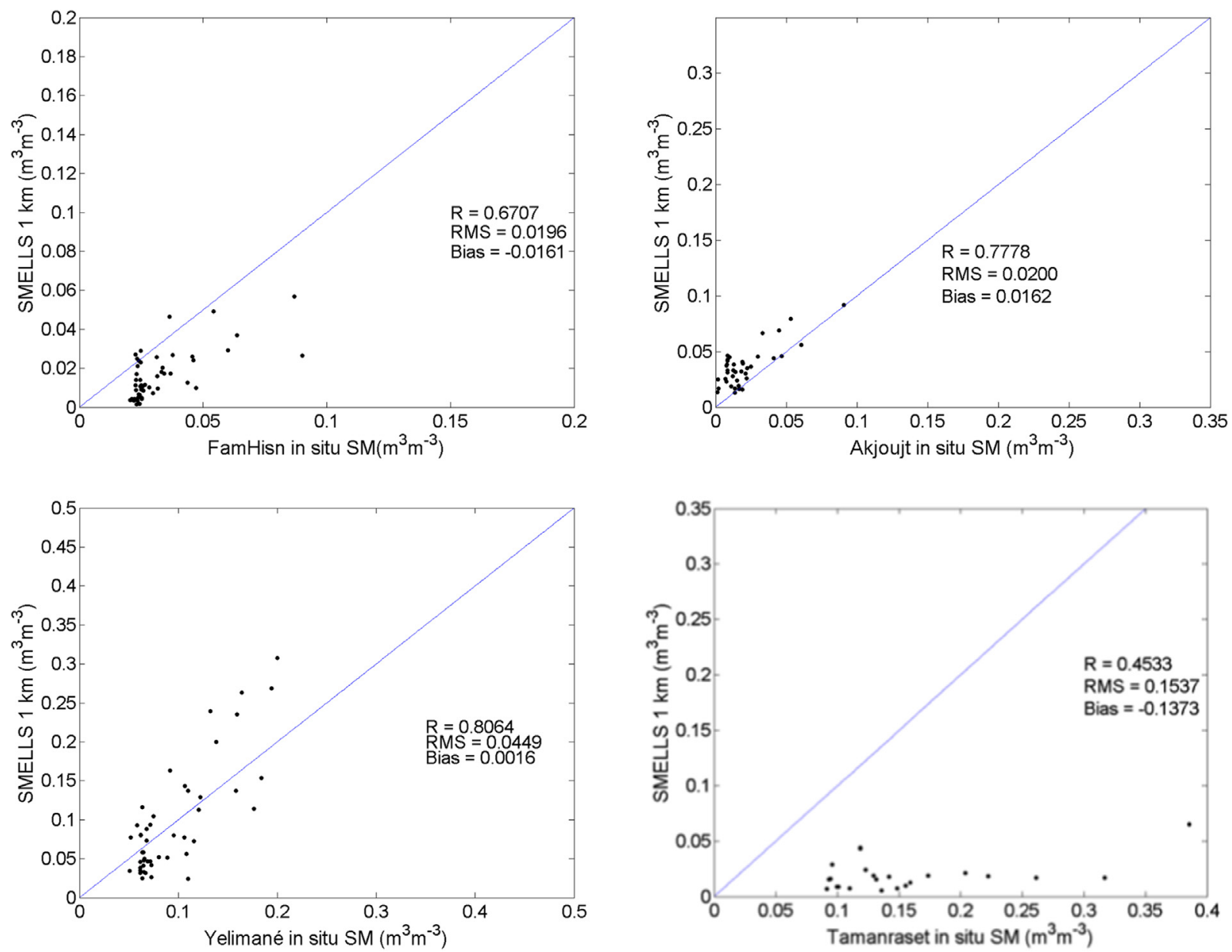

Fig. 4. in-situ correlation with SMELLS $1 \mathrm{~km}$ product for the Fam el Hisn, Akjout, Yelimané and Tamanraset soil moisture stations respectively.

Table 1

RMSE, R and bias between SMELLS $1 \mathrm{~km}$ and SMELLS in-situ SM.

\begin{tabular}{llll}
\hline & \multicolumn{2}{l}{ SMELLS 1 km product } \\
\cline { 2 - 4 } & $\mathrm{R}$ & RMSE & bias \\
\hline Akjoujt & 0.78 & 0.020 & 0.016 \\
FamHisn & 0.67 & 0.020 & -0.016 \\
Yelimane & 0.81 & 0.045 & 0.002 \\
Tamanraset & 0.45 & 0.154 & -0.138 \\
\hline
\end{tabular}

where $S M_{1} \mathrm{~km}$ is passive MW disaggregated $\mathrm{SM}$ at $1 \mathrm{~km}$ and $s m_{100 \mathrm{~m}}$ is $\mathrm{S} 1$ derived soil moisture at $100 \mathrm{~m}$.

That is, the average at $1 \mathrm{~km}$ resolution of the $100 \mathrm{~m}$ resolution soil moisture is equal to the low-resolution $(1 \mathrm{~km})$ soil moisture. It is generally acknowledged, that $\mathrm{HH}$ and VV polarizations are highly correlated with soil moisture, whereas $\mathrm{VH}$ or $\mathrm{HV}$ polarizations are considered to be more correlated with roughness and vegetation (Ulaby et al., 1986; Oh et al., 2002). However, we have applied Eqs. (5), (6) and (7) to both VV and VH polarizations. Consequently two different estimates of soil moisture at $100 \mathrm{~m}$ are obtained.

\subsection{Validation methodology}

In order to validate the soil moisture products we can envisage two approaches:

- validate the temporal representativeness of the product, this approach can only be done when long-term series of the product exist,

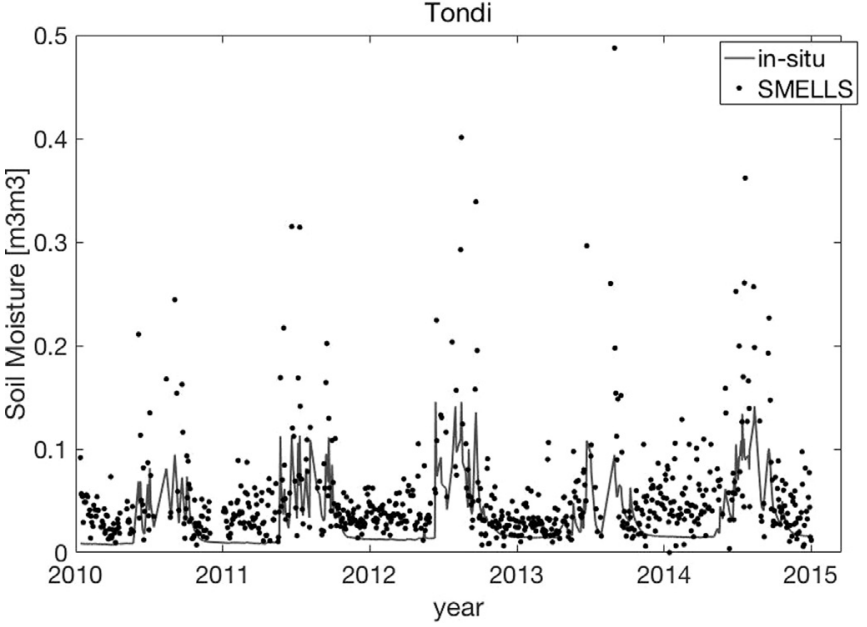

Fig. 5. Tondi in-situ measurements and SMELLS $1 \mathrm{~km}$ product temporal evolution.

- validate the spatial representativeness of the product, this approach needs validation data sampled at the same spatial scale as the product to validate.

The long time series of the SMELLS $1 \mathrm{~km}$ product allows to validate its temporal representativeness. For that purpose, the hourly ground based soil moisture observations from the SMELLS and AMMA-CATCH sites are averaged during the decadal period to match the SMELLS 
Table 2

R, RMSE and bias between SMELLS $1 \mathrm{~km}$ and AMMA in-situ SM.

\begin{tabular}{llll}
\hline \multicolumn{3}{l}{ SMELLS $1 \mathrm{~km}$ product } & \\
\cline { 2 - 4 } & $\mathrm{R}$ & $\mathrm{RMSE}$ & Bias \\
\hline Agoufou & 0.93 & 0.039 & 0.030 \\
Tondi & 0.82 & 0.046 & 0.030 \\
Wankama & 0.71 & 0.040 & 0.027 \\
Bani & 0.79 & 0.052 & 0.038 \\
\hline
\end{tabular}

products temporal sampling. When there is more than one sensor at the surface depth, the different sensor measurements are averaged. The datasets are evaluated quantitatively using the following statistics: the root mean square error (RMSE), coefficient of determination (R) and bias.

In the case of the SMELLS $100 \mathrm{~m}$ product the validation of the temporal representativeness is not possible. Indeed, a robust calibration of S1 data has not been possible before the end of the project due to a lack of wet conditions encountered in the SMELLS desert area in 2016-2017. Therefore, SMELLS $100 \mathrm{~m}$ products are scattered in time and cannot be validated against in-situ soil moisture measurements. Consequently, an initial validation of the SMELLS $100 \mathrm{~m}$ was attempted by comparing the product with a SM index based on thermal (Landsat) imagery. Similarly to Eq. (2), a thermal-derived SM index (SEE) can be obtained by normalizing the Landsat LST from the theoretical dry and wet LST values estimated from the LST-NDVI feature space (e.g. Wan
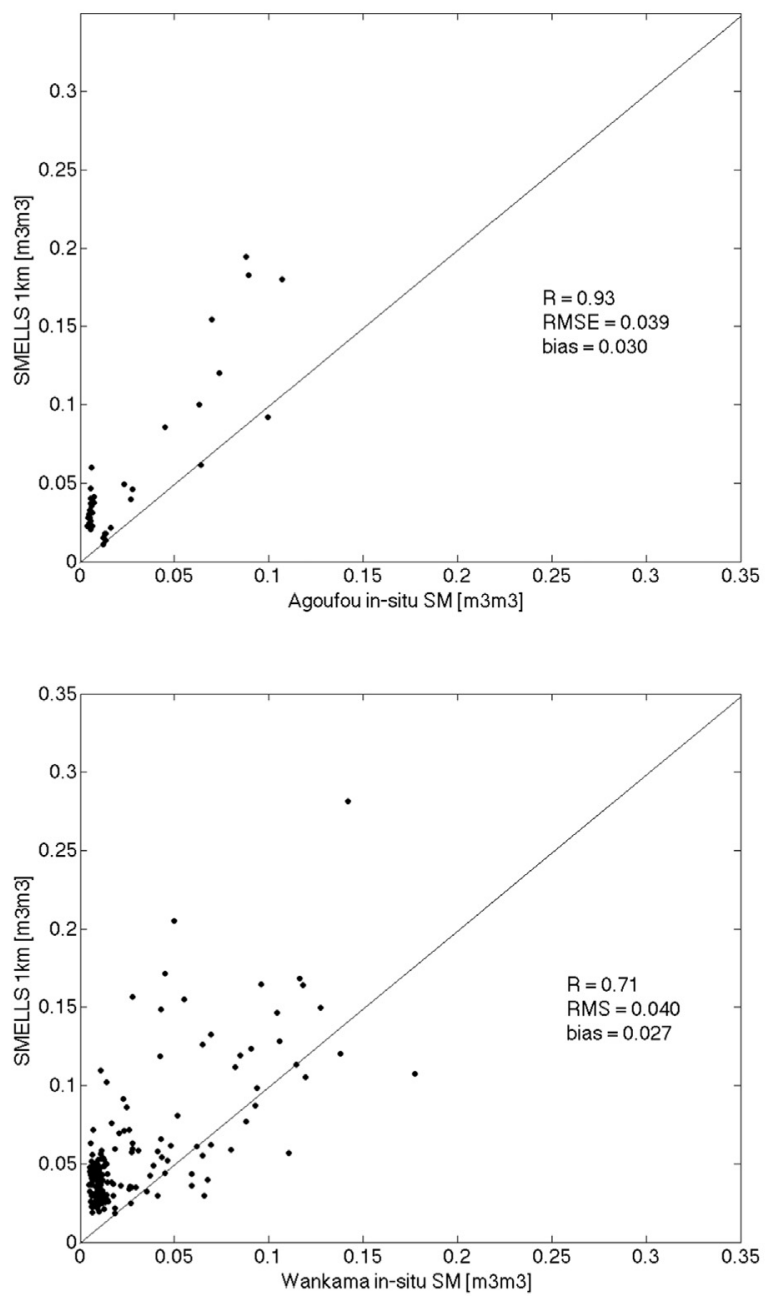

et al., 2004) or from an energy balance model (Stefan et al., 2015). Over a relatively flat terrain, in the absence of vegetation cover and under heterogeneous SM conditions (i.e. after a significant rainfall event) the dry and wet LST are approximated by the maximum and minimum observed LST value, respectively.

$S E E=\frac{L S T_{\max }-L S T}{L S T_{\max }-L S T_{\min }}$

where $L S T_{\max }$ is the maximum LST within the whole LandSat scene and $L S T_{\min }$ minimum LST within the whole LandSat scene.

\section{Results}

\subsection{SMELLS $1 \mathrm{~km}$ product}

\subsubsection{SMELLS Stations}

Fig. 3 shows the temporal evolution of the soil moisture measurements provided by the Fam el Hisn station in Morocco (two surface sensors in black and grey lines) together with daily SMELLS $1 \mathrm{~km}$ product (black dots). Soil moisture is provided in volumetric percentage expressed in $\mathrm{m}^{3} \mathrm{~m}^{-3}$ units. The surface soil moisture conditions are extremely dry with values around $0.02 \mathrm{~m}^{3} \mathrm{~m}^{-3}$. Surface sensors measurements clearly shown the impact of rain events. SMELLS product is showing also extremely dry soil moisture values and clearly captures rain events. However, some of the rain events captured by the $1 \mathrm{~km}$ SMELLS products (around DOY 480 and DOY 600) are not captured by the in-situ soil moisture stations. This could be due to precipitation
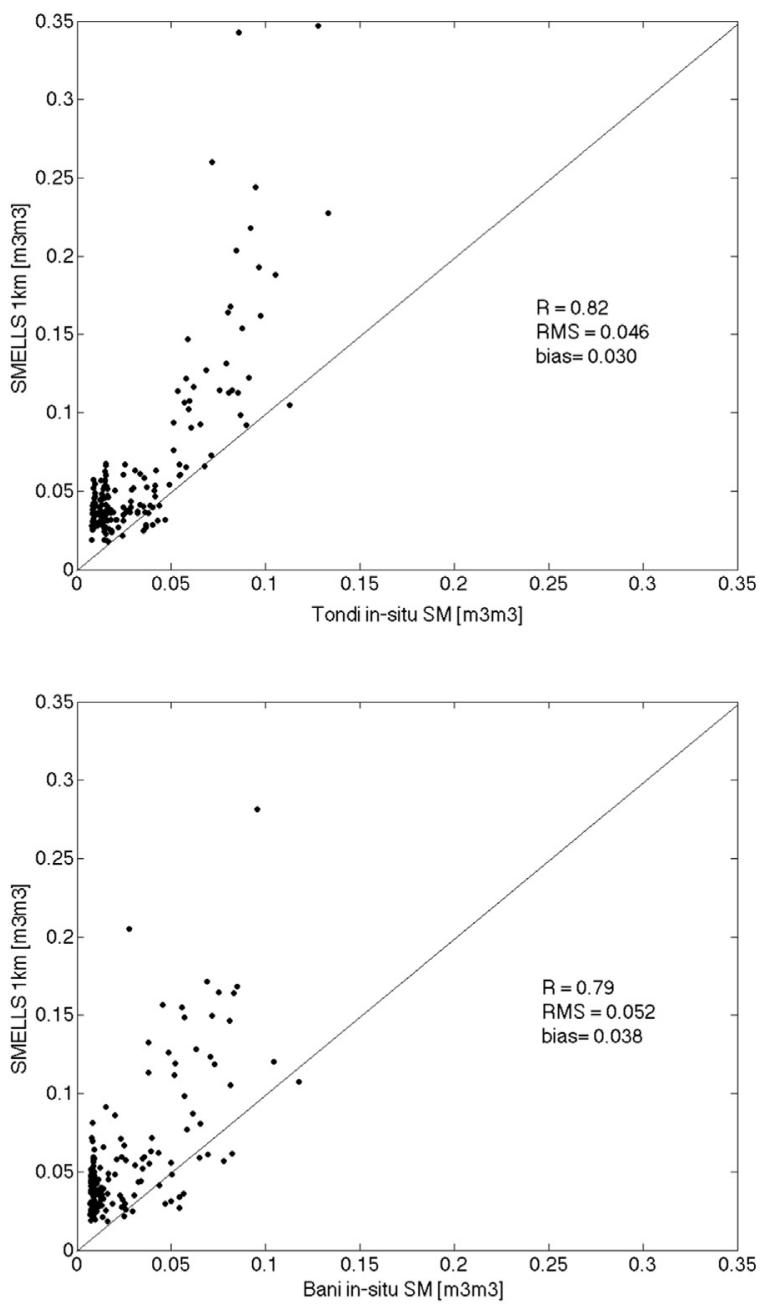

Fig. 6. in-situ correlation with SMELLS $1 \mathrm{~km}$ product for the Agoufou, Tondi, Wankama and Bani soil moisture stations respectively. 

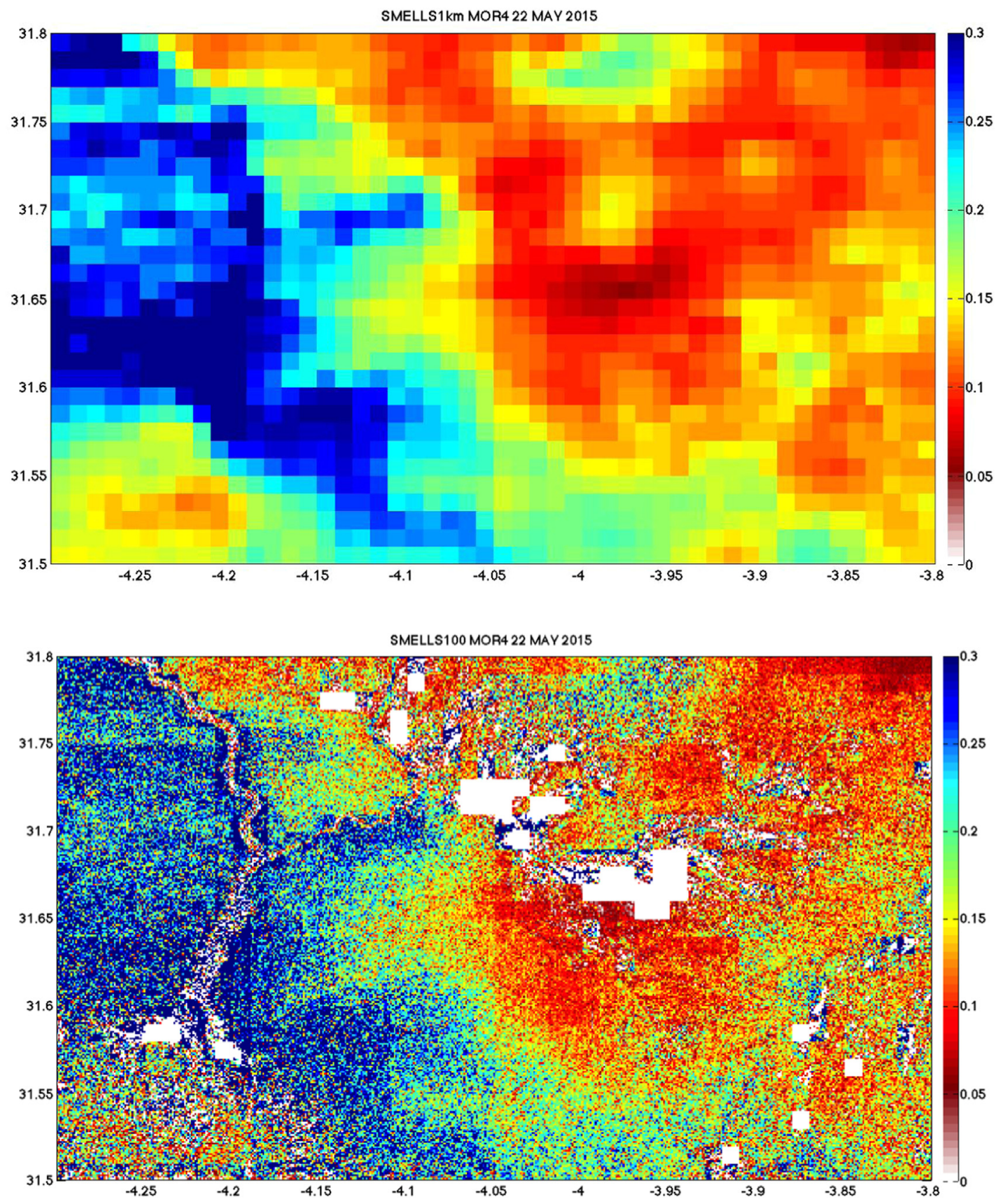

Fig. 7. Soil Moisture product at $1 \mathrm{~km}$ (upper panel) and $100 \mathrm{~m}$ (lower panel) spatial resolution on May 22th, 2015.

events very localized that did not touch where the soil moisture station is located. These precipitation events could increase the average soil moisture within the $1 \mathrm{~km}$ pixel but show no impact on soil moisture measurements by the station.

Over the Fam el Hisn station, the correlation of the SMELLS product with in-situ measurements is $\mathrm{R}=0.67$ and RMS and bias are low $0.02 \mathrm{~m}^{3} \mathrm{~m}^{-3}$ and $-0.016 \mathrm{~m}^{3} \mathrm{~m}^{-3}$ respectively. Fig. 4 is showing the correlation between the decadal SMELLS $1 \mathrm{~km}$ product and the in situ measurements at $5 \mathrm{~cm}$ depth for the Fam el Hisn, Akjoujt, Yelimané and Abalessa soil moisture stations respectively.

Over the Akjoujt station, the correlation values are good with $\mathrm{R}$ $=0.78$ and errors are low with RMS $=0.020 \mathrm{~m}^{3} \mathrm{~m}^{-3}$ and bias $=0.016 \mathrm{~m}^{3} \mathrm{~m}^{-3}$.

Over the Yelimané (Mali) station, after DOY 250 surface soil moisture sensors started an erratic behaviour that could be linked to sensor lack of adequate contact with the coarse grains (in sand). Until that date, SMELLS $1 \mathrm{~km}$ product correlation with surface soil moisture $(5 \mathrm{~cm})$ results are very good with $\mathrm{R}=0.82$ and $\mathrm{RMS}=0.042 . \mathrm{m}^{3} \mathrm{~m}^{-3}$. Further analysis is based in the comparison with the soil moisture sensor at $15 \mathrm{~cm}$. The results from that comparison are very good with $\mathrm{R}$ $=0.81$ and RMS $=0.045 \mathrm{~m}^{3} \mathrm{~m}^{-3}$ and bias $0.002 \mathrm{~m}^{3} \mathrm{~m}^{-3}$. The relatively high RMS could be due to the different sensing depth between the SMELLS products and the sensors.

Over the Abalessa station in Tamanraset, one of the surface sensors started an abnormal behaviour from DOY218 in 2016 therefore only data from the other sensor was used for the comparison. By end of 2016 both surface sensors started an abnormal behaviour. The station is located in a very remote place which impeded the reparation of the malfunction. Consequently the available dataset for the comparison is rather short. Over Tamanraset station, in-situ sensors provide an averaged value of $S M=0.10 \mathrm{~m}^{3} \mathrm{~m}^{-3}$ during the dry period and values of $\mathrm{SM}=0.50 \mathrm{~m}^{3} \mathrm{~m}^{-3}$ after a rain event. Both in-situ and remote sensed 

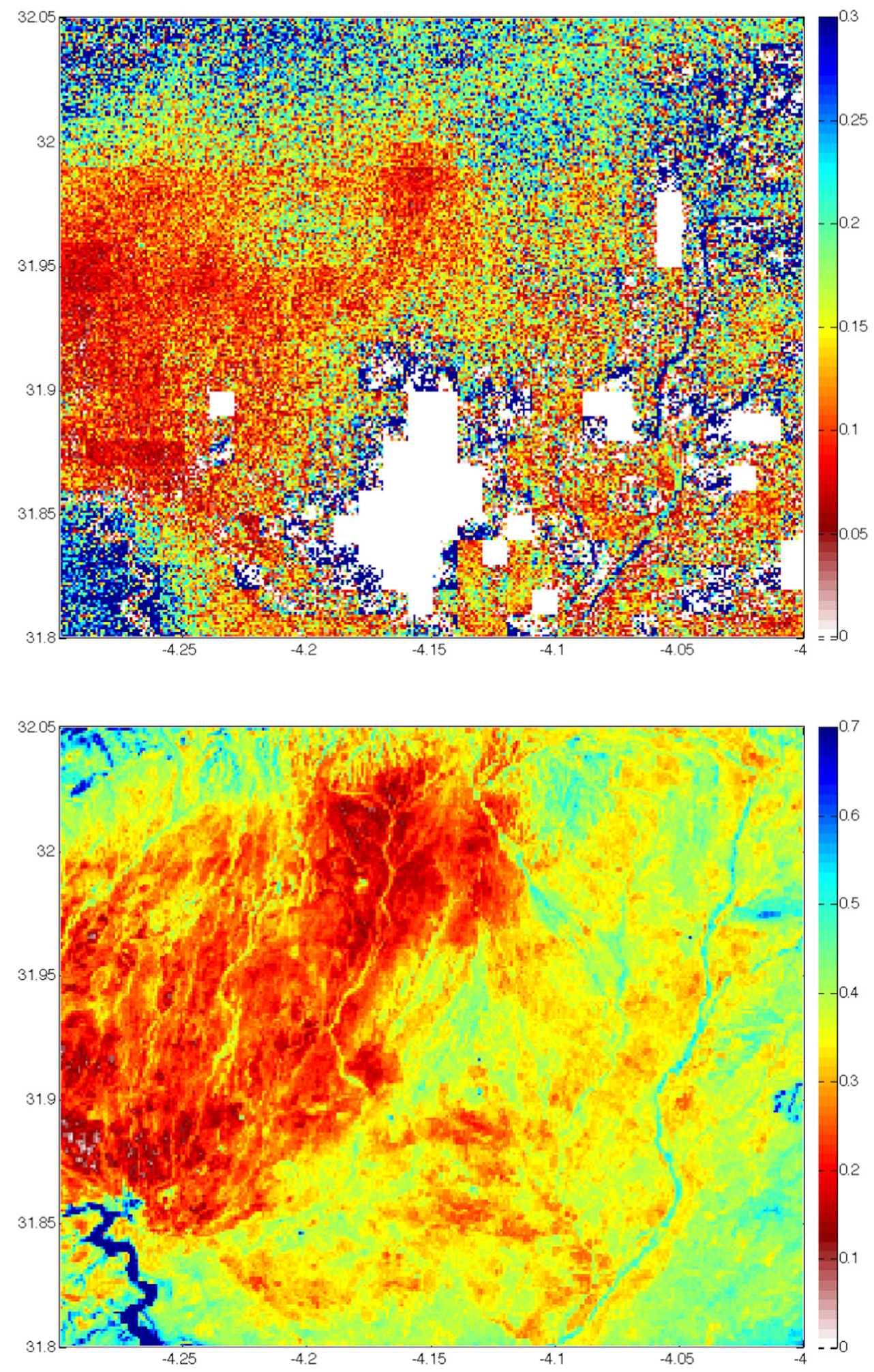

Fig. 8. SMELLS $100 \mathrm{~m}$ product (top) and SM index (SEE) (bottom) derived from Landsat TIR over a selected area in Morocco.

react simultaneously to rain events (not shown). In contrast to the other soil moisture stations, correlation values are medium $\mathrm{R}=0.45$ (could be partly due to the short time series) and RMS is high RMS $=0.154 \mathrm{~m}^{3}$ $\mathrm{m}^{-3}$ but mainly due to the high bias $\left(0.137 \mathrm{~m}^{3} \mathrm{~m}^{-3}\right)$. These results seem to indicate that the location of the station might not be representative of the $1 \mathrm{~km}$ pixel.

Table 1 summarizes the statistic results from the comparison of the $1 \mathrm{~km}$ products with the SMELLS stations.

\subsubsection{AMMA sites}

Fig. 5 shows the comparison of the SMELLS $1 \mathrm{~km}$ product over the AMMA-CATCH Tondi station. On the left panel the temporal evolution of the surface soil moisture sensor (grey line) is shown while the black dots indicate the daily available SMELLS $1 \mathrm{~km}$ product. The plot also shows that SMELLS soil moisture is noisy for extremely dry soil moisture conditions. The comparison results with the AMMA-CATCH stations are very good with values of RMSE around $0.04 \mathrm{~m}^{3} \mathrm{~m}^{-3}$ and 


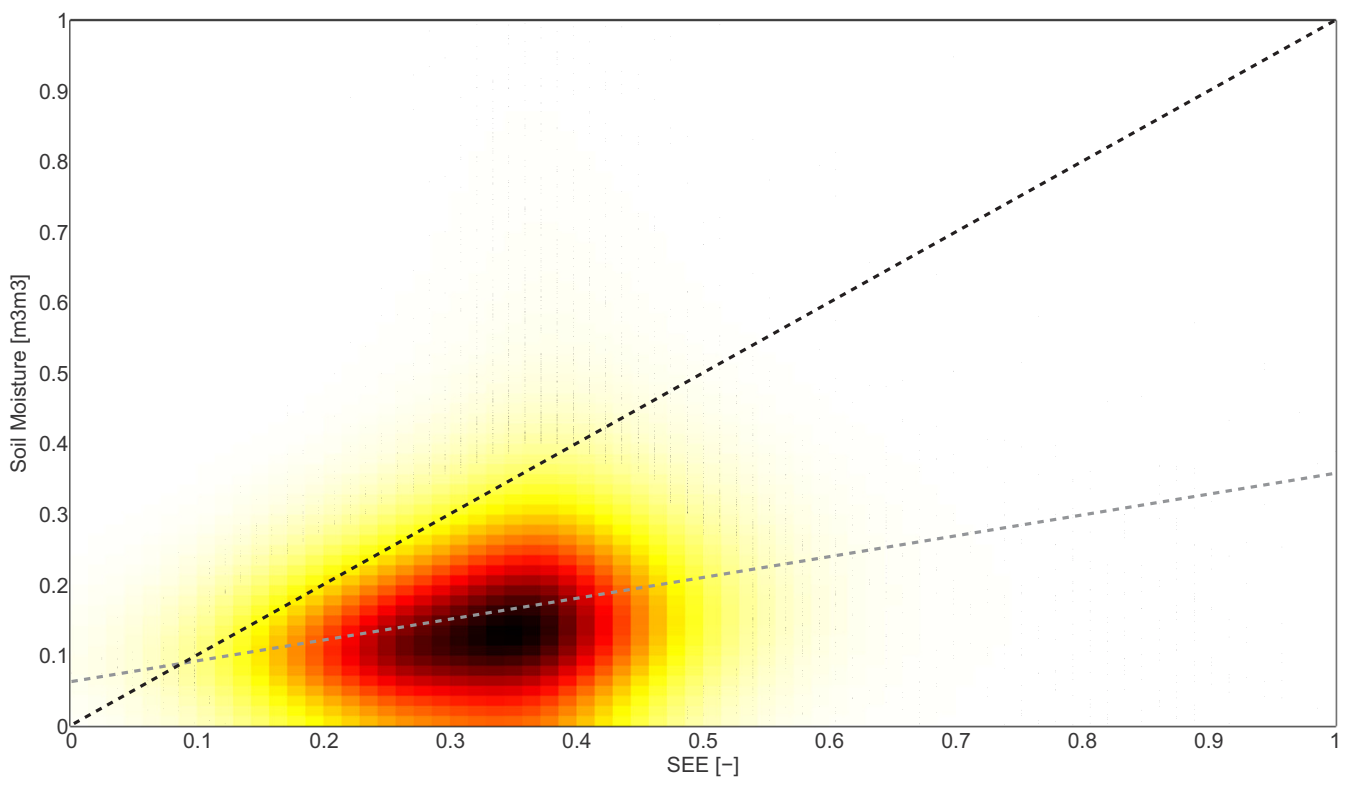

Fig. 9. SMELLS $100 \mathrm{~m}$ product comparison with SM index (SEE) derived from Landsat TIR.

$\mathrm{R}>0.80$ for the SMELLS $1 \mathrm{~km}$ product.

Table 2 summarizes the statistic results from the comparison of the $1 \mathrm{~km}$ products with the AMMA stations for both the decadal and daily products.

\subsection{SMELLS $100 \mathrm{~m}$}

The development of the Soil Moisture product at $100 \mathrm{~m}$, needs coincident SMOS and S1 acquisitions in both wet and dry soil moisture conditions. The number of acquisitions of S1 over the users areas of interest during the project development was sparse. The number of valid acquisitions was further reduced because during the summer dry period, extending from beginning June to end September, the backscatter sensitivity to soil moisture was negative. This effect, which is in contradiction with theory, has already been observed over arid and semi-arid climates. It is related to the increase of roughness due to increase of penetration depth in completely dry soils (Wanders et al., 2012; Wagner et al., 2013; Escorihuela and Quintana-Seguí, 2016). As a consequence, during the whole summer period is not possible to estimate the high resolution soil moisture based on S1 data. A generalized lack of coincident soil wet conditions with S1 acquisitions encountered in the SMELLS desert area in 2016-2017, has hindered a robust calibration of S1 algorithm.

The comparison between the high resolution soil moisture obtained from VH polarisation and VV polarisation, showed higher sensitivity (slope values) for the $\mathrm{VH}$ polarisation and, in general, also more positive slope values (i.e. the high resolution product could be retrieved for more pixels). Generally, VV polarisation is expected to be more adapted to soil moisture estimation than VH polarisation (Ulaby et al., 1986; Oh et al., 2002). Consequently, these preliminary results should be taken with care and need to be confirmed when more data are available (Fig. 6).

As an example, Fig. 7 shows the comparison between the $1 \mathrm{~km}$ and the $100 \mathrm{~m}$ soil moisture product (derived from the VH polarisation) over one user area of interest in Morocco. The figure shows that SMELLS $100 \mathrm{~m}$ product depicts higher resolution patterns that are not present in the $1 \mathrm{~km}$ product.

The proposed quantitative validation of the SMELLS $100 \mathrm{~m}$ product was restricted because we found no exact time coincidences between S1 and Landsat over the users areas of interest. The closest match between a SMELLS $100 \mathrm{~m}$ product and Landsat was between a Landsat 7 TIR image acquired over MOR4 on May 21st, 2015 and the SMELLS $100 \mathrm{~m}$ product on May 22st, 2015.

First of all, we compared the SMELLS $1 \mathrm{~km}$ product on May 21st, 2015 and on May 22nd, 2015 to the estimated SEE from Landsat aggregated at the $1 \mathrm{~km}$ scale to ensure the comparison was pertinent. Note that the comparison has to be carefully considered since a day difference is long with the evaporative demand occurring in the desert. The correlation between Landsat SEE estimate and SMELLS $1 \mathrm{~km}$ product was higher $(\mathrm{R}=0.43)$ on May 22nd, 2015 than on May 21st, 2015 indicating that the rain event was occurring after SMOS acquisition on May 21st, 2015 and therefore the comparison with SMELLS product on May 22nd, 2015 was thus pertinent. Next, in order to compare the two high resolution products we selected a relatively flat area within the two coincident footprints. Fig. 8 shows the SMELLS $100 \mathrm{~m}$ product and the LandSat 7 SEE derived over the selection area between latitudes $31.08^{\circ}$ and $32.05^{\circ} \mathrm{N}$ and longitudes $-4.30^{\circ}$ and $-4.00^{\circ} \mathrm{E}$.

The plot shows some similarities in terms of spatial structures and, in general, areas of high and low soil moisture values correspond. Fig. 9 shows the correlation plot between the SMELLS $100 \mathrm{~m}$ product on May 22nd, 2015 and SEE estimated from Landsat7 TIR on May 21st, 2015 over one user area of interest in Morocco. Correlation values are poor $(\mathrm{R}=0.28)$ at $100 \mathrm{~m}$ resolution. This could be due to uncertainties in both SMELLS $100 \mathrm{~m}$ and Landsat SM index. However, the upper edge of the point cloud is quite well defined, suggesting that a strong correlation would exist between SMELLS $100 \mathrm{~m}$ and Landsat SM index for high S1 backscatter values, corresponding to S1 data collected over flat terrain.

\section{Conclusions}

This paper presents the soil moisture products developed in the framework of desert locust management in response to authoritative end-user requirements. The SMELLS project has developed a Soil Moisture product for desert locust management at two different spatial resolutions: $1 \mathrm{~km}$ and $100 \mathrm{~m}$. The SMELLS $1 \mathrm{~km}$ product covers a vast area in West Africa including the entire Users Area of Interest between latitudes $10-40^{\circ} \mathrm{N}$ and longitudes $20^{\circ} \mathrm{W}$ to $20^{\circ} \mathrm{E}$. This long-term dataset constitutes a unique tool to evaluate the impact of this variable for Desert Locust management and is freely available on the project data portal (smells.isardsat.com/data-portal). The SMELLS $1 \mathrm{~km}$ product has been thoroughly validated and its accuracy is amongst the best soil moisture products but at a higher spatial resolution $(1 \mathrm{~km}$ against typically $40 \mathrm{~km}$ ). 
For the purpose of soil moisture validation, 4 soil moisture stations where installed in desert areas (one in each user country). Current comparison of the Soil Moisture product at $1 \mathrm{~km}$ with in-situ soil moisture stations shows good values of correlation and low RMSE except in one station where sensors showed an abnormal behaviour. The comparison results with the long-term dataset of the AMMA stations are very good with high values of correlation and RMS around $0.04 \mathrm{~m}^{3}$ $\mathrm{m}^{-3}$.

The SMELLS $100 \mathrm{~m}$ product has room for improvement. The low number of acquisitions on wet dates has limited the development of the product over the Users Areas. Since the launch of S1B in April 2016, the number of acquisitions has dramatically increased. This will surely contribute for future improvements. In situ data collected at the SMELLS cal/val sites are expected to be very useful for calibration purposes when long time series will be available.

The Soil Moisture product at $1 \mathrm{~km}$ will be integrated into the national and global Desert Locust early warning systems in national locust centres and at DLIS-FAO, respectively. The users encouraged the Soil Moisture products be extended to the entire Desert Locust recession area $(0-40 \mathrm{~N} / 20 \mathrm{~W}-80 \mathrm{E})$ because they are certain the preventive control strategy would be more effective with the introduction of these soil moisture products.

\section{Acknowledgments}

The SMELLS project was partially funded by the European Space Agency (ESA) DUE Innovators III program (contract 4000113413/15/I$\mathrm{NB})$.

\section{References}

Balenzano, A., Satalino, G., Lovergine, F., Rinaldi, M., Iacobellis, V., Mastronardi, N., Mattia, F., 2013. On the use of temporal series of l-and x-band sar data for soil moisture retrieval. capitanata plain case study. Eur. J. Remote Sens. 46, 721-737.

Brader, L., Djibo, H., Faye, F., Ghaout, S., Lazar, M., Luzietoso, P., Babah, M.O., 2006 Towards a more effective response to desert locusts and their impacts on food security, livelihoods and poverty. Multilateral evaluation of the 2003-05 Desert locust campaign. Food and Agriculture Organisation, Rome.

Cressman, K., 2013. Role of remote sensing in desert locust early warning. J. Appl. Remote Sens. 7 (075098-075098).

Cressman, K., Hodson, D., et al., 2009. Surveillance, information sharing and early warning systems for transboundary plant pests diseases: the fao experience. Arab J. Plant Prot. 27, 226-232.

De Rosnay, P., Gruhier, C., Timouk, F., Baup, F., Mougin, E., Hiernaux, P., Kergoat, L., LeDantec, V., 2009. Multi-scale soil moisture measurements at the gourma meso-scale site in mali. J. Hydrol. 375, 241-252.

Dinku, T., Ceccato, P., Cressman, K., Connor, S.J., 2010. Evaluating detection skills of satellite rainfall estimates over desert locust recession regions. J. Appl. Meteorol. Climatol. 49, 1322-1332.

Entekhabi, D., Njoku, E.G., O'Neill, P.E, Kellogg, K.H., Crow, W.T., Edelstein, W.N., Entin, J.K., Goodman, S.D., Jackson, T.J., Johnson, J., et al., 2010. The soil moisture active passive (smap) mission. Proc. IEEE 98, 704-716.

Escorihuela, M.J., Quintana-Seguí, P., 2016. Comparison of remote sensing and simulated soil moisture datasets in mediterranean landscapes. Remote Sens. Environ. 180, 99-114.

Hielkema, J.U., Popov, G., Williams, J., Saunders, R., Milford, J., 1990. Satellite environmental monitoring for migrant pest forecasting by fao: the artemis system. Philos. Trans. R. Soc. Lond. Ser. B, Biol. Sci. 705-717.

Hunter-Jones, P., 1964. Egg development in the desert locust (schistocerca gregaria forsk.) in relation to the availability of water. Physiol. Entomol. 39, 25-33.

Kerr, Y., Waldteufel, P., Wigneron, J.-P., Martinuzzi, J.-M., Font, J., Berger, M., 2001. Soil moisture retrieval from Space: the soil moisture and ocean salinity (SMOS) mission. IEEE Trans. Geosci. Remote Sens. 39 (8), 1729-1735.

Kerr, Y.H., Waldteufel, P., Richaume, P., Wigneron, J.P., Ferrazzoli, P., Mahmoodi, A., Al Bitar, A., Cabot, F., Gruhier, C., Juglea, S.E., et al., 2012. The smos soil moisture retrieval algorithm. IEEE Trans. Geosci. Remote Sens. 50, 1384-1403.

Latchininsky, A., Piou, C., Franc, A., Soti.V, V., 2016. Applications of remote sensing to locust management. Land Surf. Remote Sens.: Environ. Risks 263-294.

Lazar, M., Piou, C., Doumandji-Mitiche, B., Lecoq, M., 2016. Importance of solitarious desert locust population dynamics: lessons from historical survey data in algeria. Entomol. Exp. Et. Appl. 161, 168-180.

Louvet, S., Pellarin, T., al Bitar, A., Cappelaere, B., Galle, S., Grippa, M., Gruhier, C., Kerr, Y., Lebel, T., Mialon, A., et al., 2015. Smos soil moisture product evaluation over west-africa from local to regional scale. Remote Sens. Environ. 156, 383-394.

Magor, J., Lecoq, M., Hunter, D., 2008. Preventive control and desert locust plagues. Crop Prot. 27, 1527-1533.

Malbéteau, Y., Merlin, O., Molero, B., Rüdiger, C., Bacon, S., 2016. Dispatch as a tool to evaluate coarse-scale remotely sensed soil moisture using localized in situ measurements: application to smos and amsr-e data in southeastern australia. Int. J. Appl. Earth Obs. Geoinf. 45, 221-234.

Manabe, S., 1969. Climate and the ocean circulation 1. the atmospheric circulation and the hydrology of the earth's surface. Mon. Weather. Rev. 97, 739-774.

Masson, V., Champeaux, J.-L., Chauvin, F., Meriguet, C., Lacaze, R., 2003. A global database of land surface parameters at $1-\mathrm{km}$ resolution in meteorological and climate models. J. Clim. 16, 1261-1282.

Merlin, O., Escorihuela, M.J., Mayoral, M.A., Hagolle, O., Al Bitar, A., Kerr, Y., 2013. Selfcalibrated evaporation-based disaggregation of smos soil moisture: an evaluation study at $3 \mathrm{~km}$ and $100 \mathrm{~m}$ resolution in catalunya, spain. Remote Sens. Environ. 130, 25-38.

Merlin, O., Malbéteau, Y., Notfi, Y., Bacon, S., Khabba, S.E.-R.S., Jarlan, L., 2015 Performance metrics for soil moisture downscaling methods: application to dispatch data in central morocco. Remote Sens. 7, 3783-3807.

Merlin, O., Rudiger, C., Al Bitar, A., Richaume, P., Walker, J.P., Kerr, Y.H., 2012. Disaggregation of smos soil moisture in southeastern australia. IEEE Trans. Geosci. Remote Sens. 50, 1556-1571.

Molero, B., Merlin, O., Malbéteau, Y., Al Bitar, A., Cabot, F., Stefan, V., Kerr, Y., Bacon, S., Cosh, M., Bindlish, R., et al., 2016. Smos disaggregated soil moisture product at $1 \mathrm{~km}$ resolution: processor overview and first validation results. Remote Sens. Environ. 180, 361-376.

Moran, M.S., Clarke, T.R., Inoue, Y., Vidal, A., 1994. Estimating crop water deficit using the relation between surface-air temperature and spectral vegetation index. Remote Sens. Environ. 49, 246-263.

Njoku, E., Jackson, T., Lakshmi, V., Chan, T., Nghiem, S., 2003. Soil moisture retrieval from AMSR-E. IEEE Trans. Geosci. Remote Sens. 41, 215-229.

Oh, Y., Jang, Y., Sarabandi, K., 2002. Full-wave analysis of microwave scattering from short vegetation: an investigation on the effect of multiple scattering. IEEE Trans. Geosci. Remote Sens. 40, 2522-2526.

Pekel, J.-F., Ceccato, P., Vancutsem, C., Cressman, K., Vanbogaert, E., Defourny, P., 2011. Development and application of multi-temporal colorimetric transformation to monitor vegetation in the desert locust habitat. IEEE J. Sel. Top. Appl. Earth Obs. Remote Sens. 4, 318-326.

Pellarin, T., Laurent, J.-P., Cappelaere, B., Decharme, B., Descroix, L., Ramier, D., 2009. Hydrological modelling and associated microwave emission of a semi-arid region in south-western niger. J. Hydrol. 375, 262-272.

Pener, M.P., Simpson, S.J., 2009. Locust phase polyphenism: an update. Adv. Insect Physiol. 36, 1-272.

Renier, C., Waldner, F., Jacques, D.C., Babah Ebbe, M.A., Cressman, K., Defourny, P. 2015. A dynamic vegetation senescence indicator for near-real-time desert locust habitat monitoring with modis. Remote Sens. 7, 7545-7570.

Satalino, G., Balenzano, A., Mattia, F., Davidson, M.W., 2014. C-band sar data for mapping crops dominated by surface or volume scattering. IEEE Geosci. Remote Sens. Lett. 11, 384-388.

Stefan, V.G., Merlin, O., Er-Raki, S., Escorihuela, M.-J., Khabba, S., 2015. Consistency between in situ, model-derived and high-resolution-image-based soil temperature end members: towards a robust data-based model for multi-resolution monitoring of crop evapotranspiration. Remote Sens. 7, 10444-10479.

Sword, G.A., Lecoq, M., Simpson, S.J., 2010. Phase polyphenism and preventative locust management. J. Insect Physiol. 56, 949-957.

Torres, R., Snoeij, P., Geudtner, D., Bibby, D., Davidson, M., Attema, E., Potin, P., Rommen, B., Floury, N., Brown, M., et al., 2012. Gmes sentinel-1 mission. Remote Sens. Environ. 120, 9-24.

Ulaby, F., Moore, R., Fung, A., 1986: Microwave remote sensing: active and passive, Vol III, from theory to application. Artech House, Dedham, MA.

Uvarov, B., 1921. A revision of the genus locusta, 1.(= pachytylus, fieb.), with a new theory as to the periodicity and migrations of locusts. Bull. Ėntomol. Res. 12, $135-163$.

Wagner, W., Hahn, S., Kidd, R., Melzer, T., Bartalis, Z., Hasenauer, S., Figa-Saldaña, J., de Rosnay, P., Jann, A., Schneider, S., et al., 2013. The ascat soil moisture product: a review of its specifications, validation results, and emerging applications. Meteorol. Z. 22, 5-33.

Wagner, W., Lemoine, G., Rott, H., 1999. A method for estimating soil moisture from ers scatterometer and soil data. Remote Sens. Environ. 70, 191-207.

Waldner, F., Ebbe, M.A.B., Cressman, K., Defourny, P., 2015. Operational monitoring of the desert locust habitat with earth observation: an assessment. ISPRS Int. J. Geo-Inf. 4, 2379-2400

Wan, Z., Wang, P., Li, X., 2004. Using modis land surface temperature and normalized difference vegetation index products for monitoring drought in the southern great plains, USA. Int. J. Remote Sens. 25, 61-72.

Wanders, N., Karssenberg, D., Bierkens, M., Parinussa, R., de Jeu, R., van Dam, J., de Jong, S., 2012. Observation uncertainty of satellite soil moisture products determined with physically-based modeling. Remote Sens. Environ. 127, 341-356.

Zribi, M., Chahbi, A., Shabou, M., Lili-Chabaane, Z., Duchemin, B., Baghdadi, N., Amri, R., Chehbouni, A., 2011. Soil surface moisture estimation over a semi-arid region using envisat asar radar data for soil evaporation evaluation. Hydrol. Earth Syst. Sci. Discuss. 15, 345-358. 